\title{
HAIRY CARBON ELECTRODES \\ STUDIED BY CYCLIC VOLTAMMETRY AND BATTERY DISCHARGE TESTING
}

\author{
Deborah D. L. Chung and Xiaoping Shui \\ Composite Materials Research Laboratory, State University of New York at Buffalo \\ Buffalo, NY 14260-4400 \\ Christine A. Frysz \\ Technology Division, Wilson Greatbatch, Ltd. \\ 10,000 Wehrle Drive, Clarence, NY 14031
}

\begin{abstract}
Hairy carbon is a new material developed by growing submicron carbon filaments on conventional carbon substrates. Typical substrate materials include carbon black, graphite powder, carbon fibers and glassy carbon. A catalyst is used to initiate hair growth with carbonaceous gases serving as the carton source. To study the electrochemical behavior of hairy carbons, cyclic voltammetry $(\mathrm{CV})$ and discharge testing were conducted. In both cases, hairy carbon results surpassed those of the substrate material alone.
\end{abstract}

\section{INTRODUCTION}

Because carbon and graphite exhibit an advantageous blend of chemical, electrical, mechanical and thermal properties, they are very often considered for electrochemical applications. Chemically, carbon and graphite offer good corrosion resistance, are available in high purity and readily form intercalation products. Not only are they good electrical conductors, but they also exhibit high thermal conductivity and low thermal expansion. Carbon and graphite are lightweight, easily handled, and are also available in a variety of physical structures including carbon fibers, submicron carbon filaments, carbon blacks and graphite powders. The battery electrode is among the electrochemical applications requiring the characteristics just described.

Military, space and commercial applications continue to become more and more demanding. Today's technological strides require that batteries be compact but capable of providing higher energy and power density while still maintaining long shelf life and good discharge characteristics. Continued advancement in carbon and graphite technology can contribute toward achieving these goals by providing improvements to the characteristics that most influence performance.

Hairy carbon, a new material comprising tiny carbon filaments grown on conventional carbon substrates, have been developed. The hairs on the carbon are submicron filaments with diameters ranging between $0.05 \mu \mathrm{m}$ and $0.2 \mu \mathrm{m}$. Figures $1 \mathrm{a}$ and $\mathrm{b}$ are scanning electron photomicrographs of hairy carbon grown on carbon black. Two different magnifications of the same sample are displayed. At the lower magnification, Figure 1a, a small portion of a hairy carbon black cluster is shown. The submicron nature of the hairs can very easily be seen at the higher magnification presented in Figure $1 \mathrm{~b}$.

Hairy carbons are not to be confused with conventional carbon fibers or carbon filaments as developed by Tibbetts and coworkers at General Motors. ${ }^{1-3}$ Whereas hairy carbon is catalytically grown from carbonaceous gases, carbon fibers are typically prepared either from a pitch material or from a polymer precursor such as polyacrylonitrile. In contrast to hairy carbon, carbon fibers have diameters of the order of $10 \mu \mathrm{m}$. Carbon filaments, like hairy carbon, are submicron in nature (typical diameters of $0.2 \mu \mathrm{m}$ ) and are also catalytically grown from carbonaceous source gases, but carbon filaments are very long and tend to cling to each other as does cotton wool. Consequently, dispersion and mixing are very difficult. Since hairy carbons can be produced on particulate carbon substrates, the particulate nature of the finished product is preserved. Dispersion and mixing, therefore, remain very easy. An added advantage is that the length of the 'hair' can be easily controlled gearing the finished product toward the intended application. In fact, the hairs can be so short that they resemble nodules. 
Carbon filaments, like hairy carbon, can be grown using carbon monoxide or many different hydrocarbons as the source. ${ }^{4-10}$ Methane and other aliphatics, olefins, and aromatics have all been shown to produce carbon filaments when exposed to appropriate catalysts. The presence of gases which can gasify carbon (hydrogen, water, carbon dioxide) reduces the driving force and lowers the rate of filament growth, ultimately stopping it completely. Carbon filament formation takes place under conditions where, in the absence of the 'catalyst,' no carbon deposition would take place.

Hairy carbon can easily satisfy two battery electrode applications: (1) a reduction electrode when used independent of other cathode mixes; and, (2) a conductive additive to otherwise nonconductive or low conductivity cathode mixes such as manganese dioxide and carbon monofluoride. For the former application, the submicron filamentous nature of the carbon can provide a novel means for controlling connectivity, porosity and surface area. These attributes, along with the improved physical properties, offer advantages over state-of-the-art carbon electrodes. Regarding the latter application, hairy carbon, being more graphitic and exhibiting high aspect ratio, in addition to improving electrical conductivity, could result in the addition of a smaller volume fraction for conductivity enhancement allowing for addition of more active cathode material or reduction in overall cathode size. The end result is high power and high energy density composite cathodes with more energy output from the same package design or equal energy output from more compact designs. This could prove beneficial to implantable device manufacturers, space exploration programs and original equipment manufacturers requiring size and weight constraints or increased energy from current design packages. This paper focuses on the former application, that is, the carbon reduction electrode. Discharge testing was conducted in BCX electrolyte. BCX is a codepolarizer of the interhalogen, bromine chloride, in thionyl chloride. ${ }^{11}$

\section{EXPERIMENTAL}

The electrochemical behavior of the hairy carbons was studied using cyclic voltammetry (CV). A Bioanalytical Systems CV cell, Figure 2, was used in conjunction with the Headstart Electrochemistry program (developed by EG\&G Princeton Applied Research), a potentiostat and an IBM personal computer. A saturated calomel electrode served as reference with a platinum wire used as the auxiliary electrode. The working electrode was a purchased holder typically used for carbon paste electrodes. The hairy carbon filled the cavity as does carbon paste, however, was used without the conventional paraffin oil binder. Testing was conducted in $6 \mathrm{mM}$ potassium ferrocyanide as the electroactive species in $1 \mathrm{M}$ potassium nitrate in water as the supporting electrolyte. This solution allowed study of the $\mathrm{Fe}^{2+} / \mathrm{Fe}^{3+}$ redox couple.

To assess the discharge capability of hairy carbon, constant current plate to plate discharge testing was conducted using the apparatus shown in Figure 3. A cut-down AA battery case was used as the positive electrode current collector. The hairy carbon was placed inside the case and separated from the lithium by a nonconductive glass fiber paper. Insulative polymer disks were placed on top of the assembly and held in place with a metal clip. The assembly was immersed in the BCX electrolyte. A Keithley power source was used to apply current. Data was collected on a Tandy computer.

\section{RESULTS AND DISCUSSION}

Compared in Figures $4 \mathrm{a}$ - $\mathrm{f}$ are the voltammetric responses for hairy versus plain graphite powder, hairy versus plain carbon black and hairy versus plain carbon fibers. The addition of hair dramatically improves electrochemical performance. Note the increase in electron transfer rate and enhanced reversibility of the redox reactions. The improvements are attributed to increased surface area and particulate connectivity which translates into improved conductivity. Figures $5 \mathrm{a}$ and $\mathrm{b}$ compare a cyclic voltammogram of conventional carbon paste using paraffin oil with dry hairy graphite powder. The graphite powder used to grow hairs for this experiment was the same powder used to manufacture the carbon paste commercially available for analytical electrodes. The results indicate that the electrochemical response of the dry hairy graphite powder surpasses that of current carbon paste technology. 
Discharge performance using hairy versus plain graphite powder is shown in Figure 6. An improvement in cell capacity per unit area of greater than $100 \%$ was achieved using hairy graphite powder. The substantial increase in capacity is attributed to increased electrode surface area as well as conductivity. The significance in this result is the fact that the graphite powder tested would never be considered for lithium battery use primarily because of its low surface area. Given these results and that many varieties of carbon forms can be made hairy, a new group of materials become available for research by battery manufacturers.

In addition to surface area, pore size and distribution are of importance for carbon reduction electrodes. Carbon blacks traditionally exhibit high surface areas. Electrode preparation methods are developed to achieve optimum electrode pore size and distribution. To maintain good electrode pore size and distribution, yet assess the effect of increased electrode conductivity, discharge testing of carbon black electrodes employed blends of plain carbon black with hairy carbon black. The plain carbon black provided retention of good pore size and distribution while the hairy carbon black contributed to electrode conductivity. Figure 7 compares discharge performance of plain carbon black with a blend of 50 weight percent hairy carbon black and 50 weight per cent plain carbon black. An improvement of approximately $40 \mathrm{~mA} \cdot \mathrm{h}$ per unit density was achieved when discharged to 2 volts.

\section{CONCLUSIONS}

Hairy carbon is electrochemically superior to plain carbon whether in the form of carbon black, graphite powder or carbon fibers. Hairy carbon can improve electrode performance as observed by plate to plate discharge testing. Compared to plain graphite powder deemed unusable for battery applications, hairy graphite powder used in a lithium soluble cathode system, BCX, as a reduction electrode shows increased capacity by greater than $100 \%$. The capacity of electrodes made with a blend of hairy carbon black and plain carbon black was also improved. Capacity improvements due to hairy carbon, however, are larger for graphite powder than for carbon black. The difference in improvement is attributed to increased electrode surface area as well as conductivity on graphite powder whereas conductivity alone is increased for hairy carbon black. Hairy carbon is a new material. Its electrochemical behavior shows it to be attractive for electrode use. In addition to offering a variety of new materials for research by battery manufacturers, the improved electrochemical responses make hairy carbon desirable candidates for analytical electrodes, be they chemical or biomedical. Other potential applications include electronic thermal conductors and conductive composites.

\section{ACKNOWLEDGMENTS}

The authors would like to thank New York State Energy Research and Development Authority for funding this work and Professor Carl R. F. Lund of SUNY/Buffalo for technical assistance in hair growth.

\section{REFERENCES}

1. Tibbetts, G. G., Cryst, J., Growth, 66, 632 (1984).

2. Tibbetts, G. G., DeVour, M. G., and Rodda, E. J., Carbon, 25, 367 (1987).

3. Bradley, J. R., and Tibbetts, G. G., Carbon, 23, 423 (1985).

4. Keep, C. W., Baker, R. T. K., and France, J. A., Journal of Catalysis, 47, 232 (1977).

5. Baker, R. T. K., Barber, M. A., Harris, P. S., Feates, F. S., and Waite, R. J., Journal of Catalysis, 26, 51 (1972).

6. Rostrup-Nielsen, J. R., Journal of Catalysis, 27, 343 (1972). 
7. Oberlin, A., Endo, M., and Koyama, T., Journal of Crystal Growth, 32, 335 (1976).

8. Jackson, S. D., Thompson, S. J., and Webb, G., Journal of Catalysis, 70, 249 (1981).

9. Audier, M., and Coulon, M., Carbon, 23, 317 (1985).

10. Lobo, L. S., and Trimm, D. L., Journal of Catalysis, 29, 15 (1973).

11. C. C. Liang, P. Krehl, D. A. Danner, Journal of. Applied Electrochemistry, 11, (1981) 563-571. 

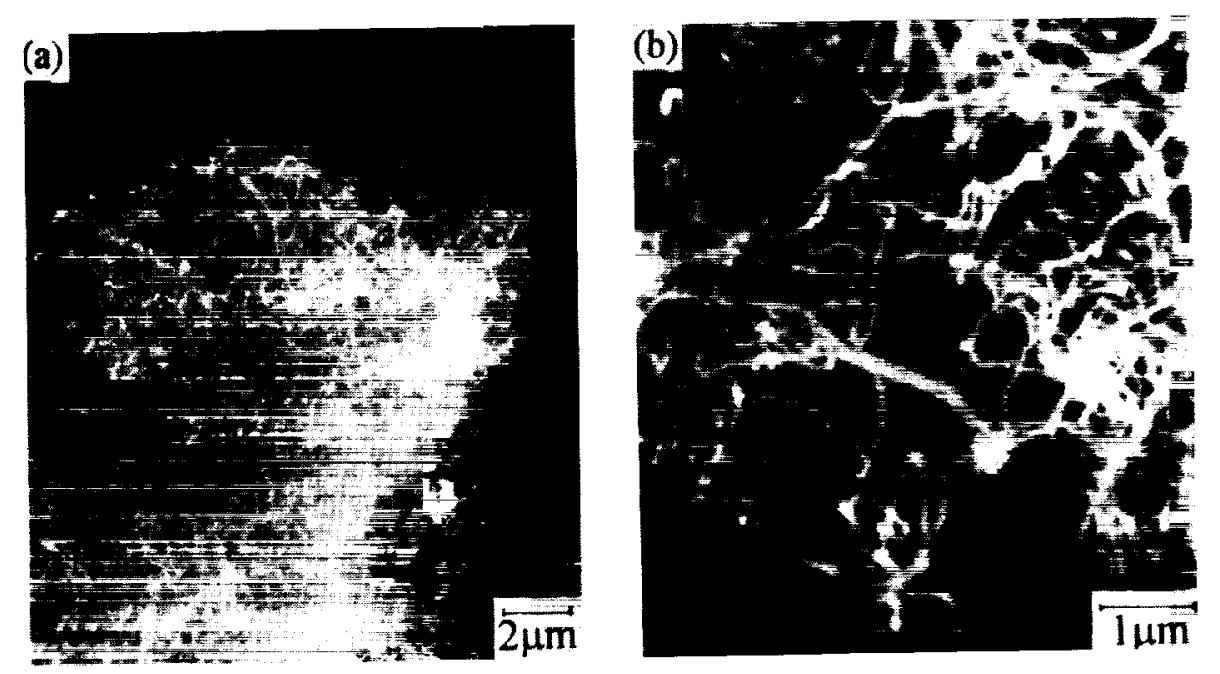

Figure 1 - Scanning electron photomicrographs of hairy carbon black. A portion of a cluster of hairy carbon black is shown in (a). The submicron nature of the hairs is readily observed in the higher magnification view in (b).

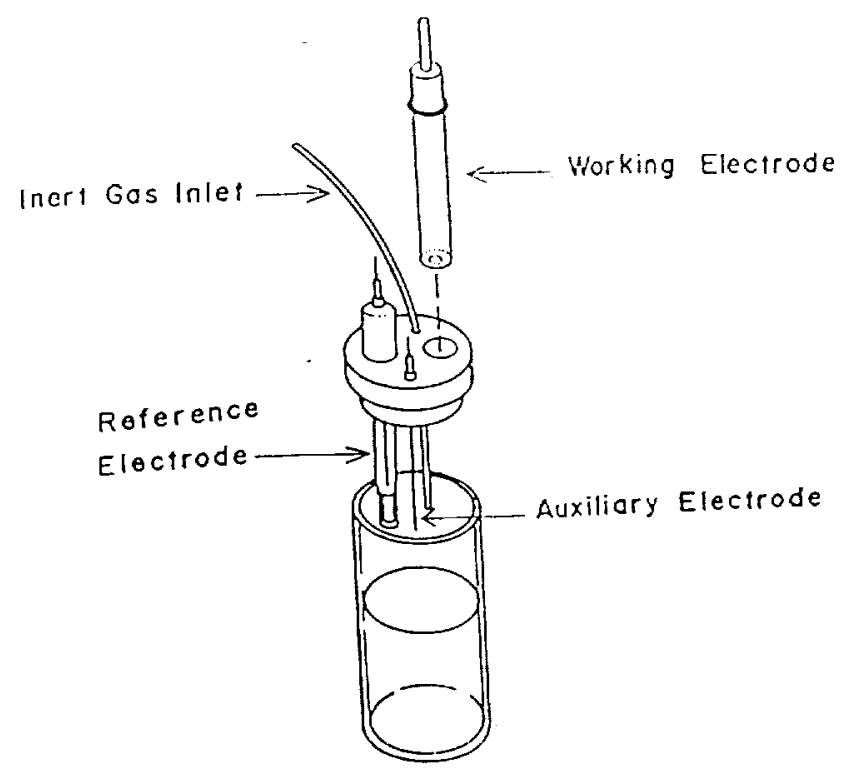

Figure 2 - The cyclic voltammetry cell used to study the $\mathrm{Fe}^{2+} / \mathrm{Fe}^{3+}$ redox couple.
GLASS MICROSCOPE SL IOE

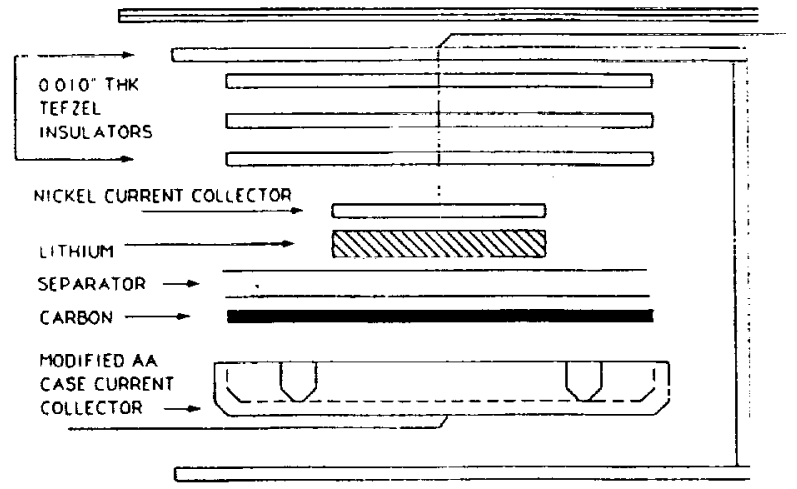

Figure 3 - Hairy carbon discharge test cell. Capacity comparisons were made by conducting plate to plate discharge testing. 

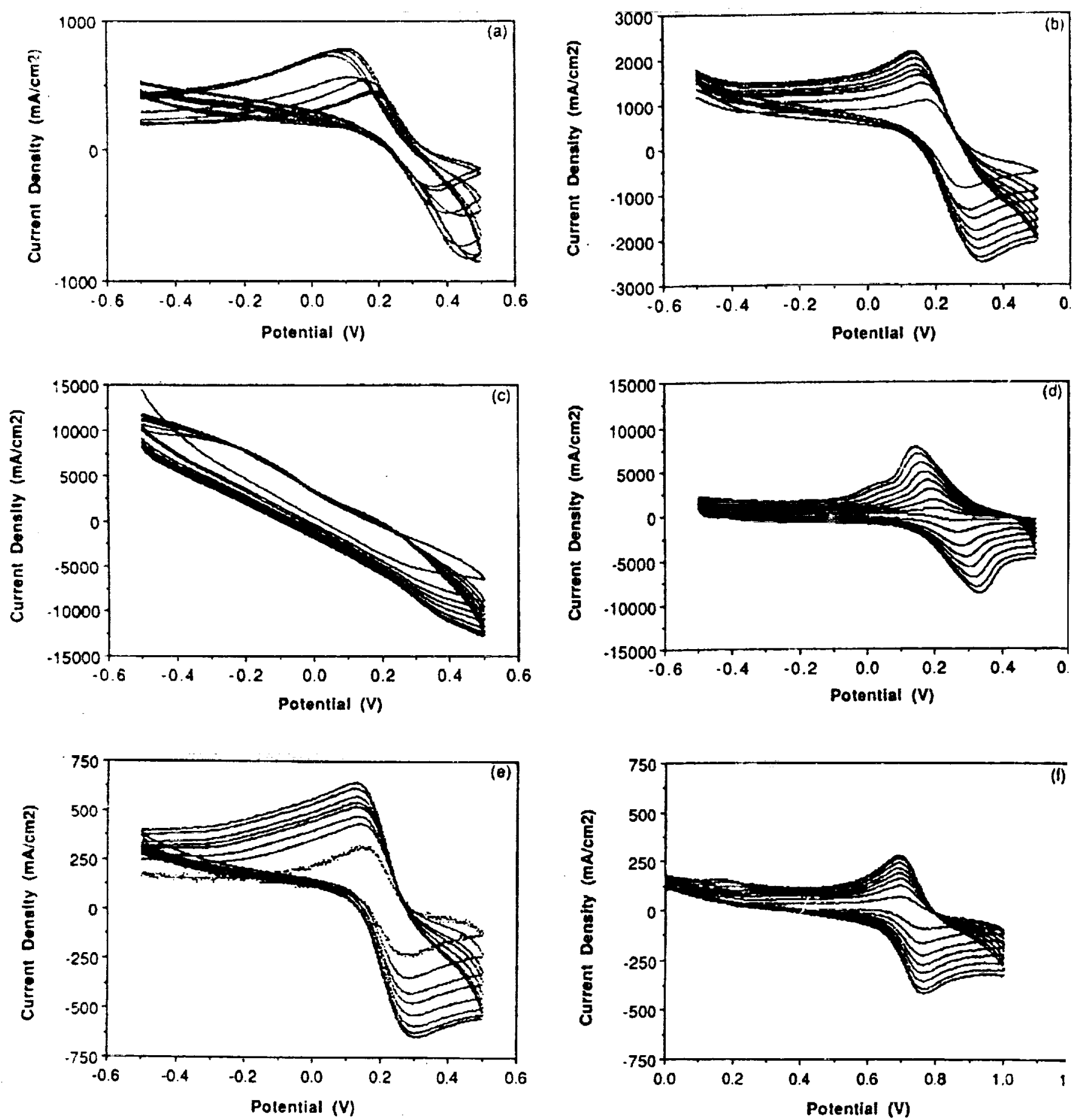

Figure 4 Cyclic voltammograms of plain versus hairy carbon substrates. Plain versus hairy graphite powder is compared in (a) and (b) respectively, plain versus hairy carbon black in (c) and (d) respectively, and plain versus hairy carbon fibers in (e) and (f) respectively. 

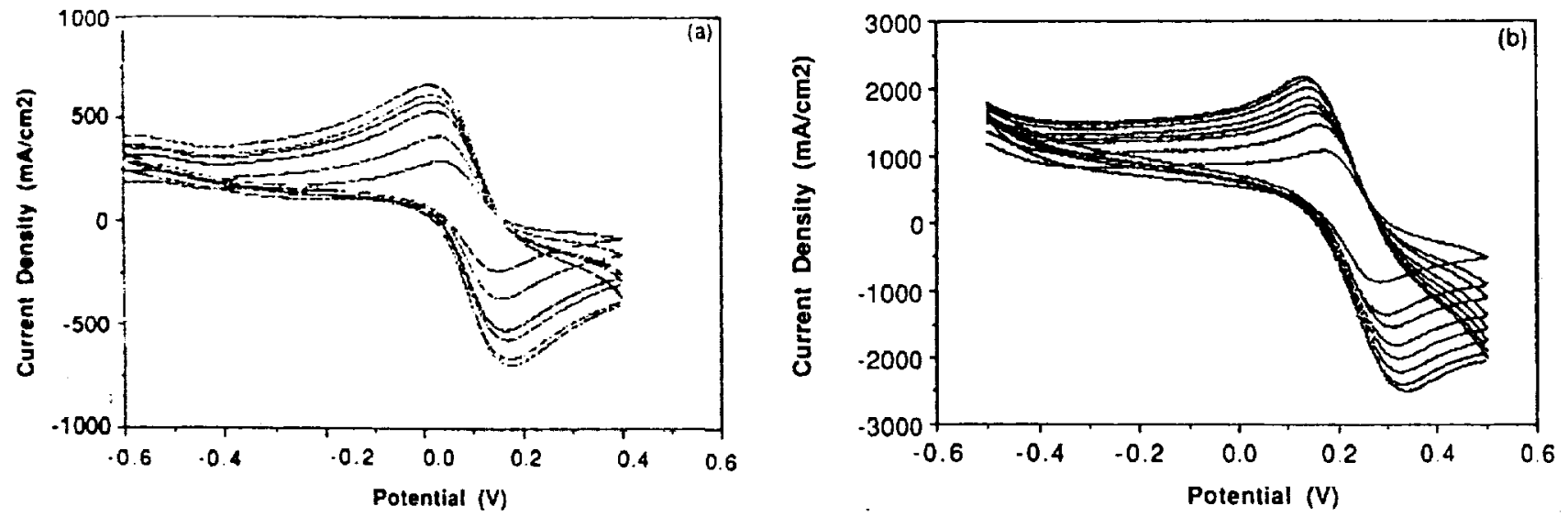

Figure 5 - Cyclic voltammetry comparison between conventional carbon paste using paraffin oil binder (a) and dry hairy graphite powder (b). The

graphite powder for both (a) and (b) is the same except that the powder in (b) is hairy.

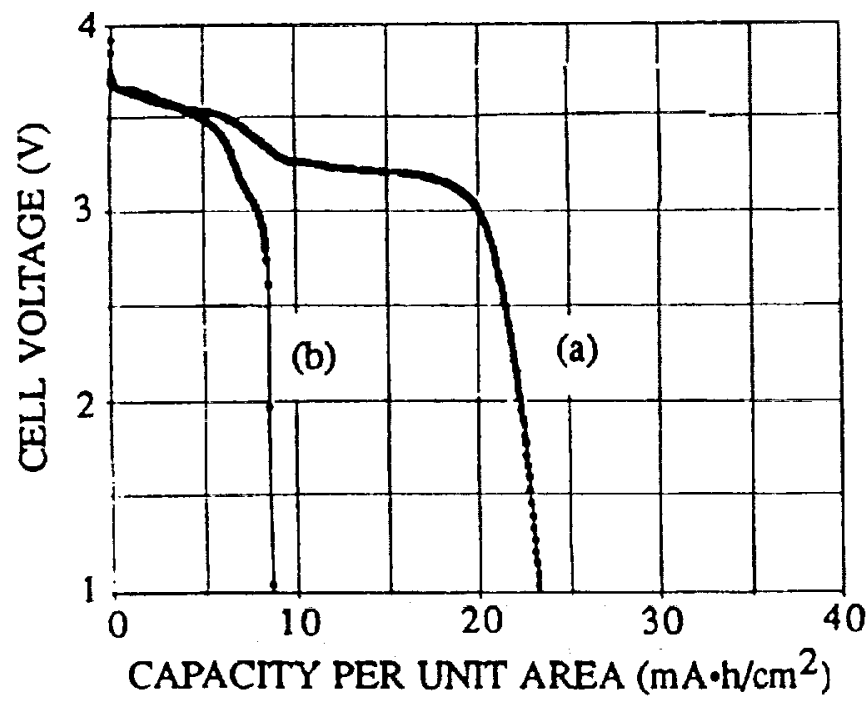

Figure 6 - Plate to plate discharge test results for (a) hairy and (b) plain graphite powder. The plain graphite powder is not used by battery manufacturers because of its low surface area.

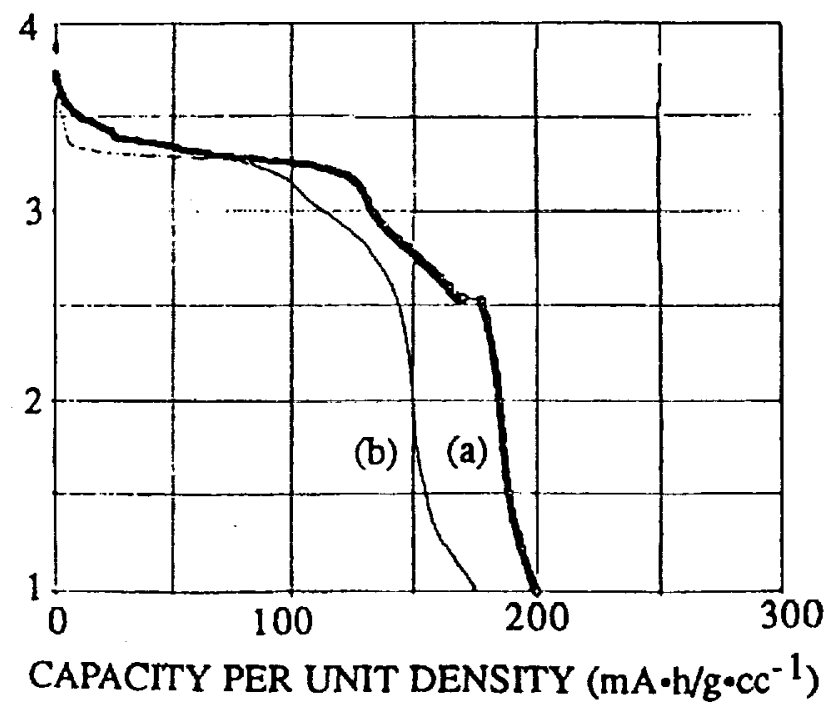

Figure 7 - Plate to plate discharge test results for (a) hairy and (b) plain carbon black. The hairy carbon black electrode is a 50:50 blend by weight of hairy carbon black with plain carbon black. 
Public reporting burden for this collection of information is estimated to average 1 hour per response, fncluding the time for reviewing lnstructions, searching existing data sources, gathering and maintaining the data needed, and completing and revlewing the collection of information. Send comments regarding this burden estimate or any other aspect of this collection of inlormatton, including sugesstions for reducing this burden, to Washington Headquarters Services, Directorate for Information Operations and Reports, 1215 Jefferson Davis Highway, Sulte 1204, Arlington, VA 22202-4302, and to the Otfice of Management and Budget, Paperwork Reduction Project (0704-0188), Washington, DC 20503.
1. AGENCY USE ONLY (Laave blank)
2. REPORT DATE
November 1993
3. REPORT TYPE AND DATES COVERED
Conference Publication

\section{TITLE AND SUBTTILE}

Space Electrochemical Research and Technology
5. FUNDING NUMBERS

WU-506-41-21

6. AUTHOA(S)

8. PERFORTING ORGANZATON REPORT NUMBER

E-8075

Lewis Research Center

Cleveland, Ohio 44135-3191

9. SPONSORING/WONITORING AGENCY NAME(S) AND ADDRESS(ES)

10. SPONSORINGIIONTORING AGENCY REPOAT NUMBER

National Aeronautics and Space Administration

Washington, D.C. 20546-0001

NASA CP-3228

\section{SUPPLEMENTARY NOTES}

Responsible person, Margaret A. Reid, (216) 433-5253.

12a. DISTAIBUTION/AVALABILTY STATEMENT

12b. DISTRIBUTION CODE

Unclassified-Unlimited

Subject Categories 44 and 02

13. ABSTRACT (MaxImum 200 words)

This document contains the proceedings of NASA's fourth Space Electrochemical Research and Technology (SERT) Conference, held at the NASA Lewis Research Center on April 14-15, 1993. The objective of the conference was to assess the present status and general thrust of research and development in those areas of electrochemical technology required to enable NASA missions into the next century. The conference provided a forum for the exchange of ideas and opinions of those actively involved in the field, in order to define new opportunities for the application of electrochemical processes in future NASA missions. Papers were presented in three technical areas: advanced secondary batteries, fuel cells, and advanced concepts for space power. This document contains the papers presented.

\section{SUBJECT TERMS}

Electrochemistry; Batteries; Fuel cells 269

17. SECUAITY CLASSIFICATION OF REPOAT

Unclassified

\section{SECURITY CLASSIFICATION OF THIS PAGE \\ Unclassified}

\section{SECUATY CLASSIFICATION} OF ABSTRACT Unclassified 